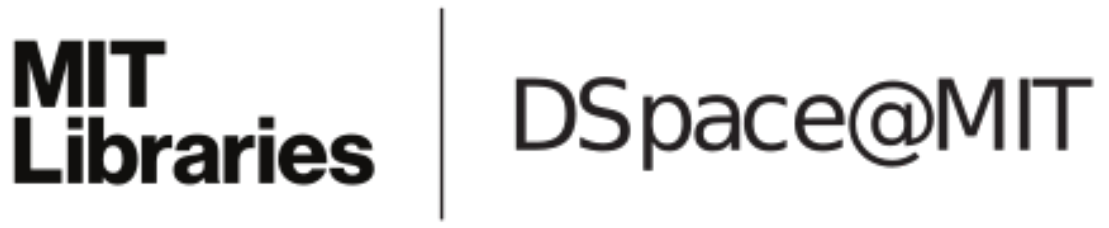

\author{
MIT Open Access Articles \\ InGaP solar cell on Ge-on-Si virtual \\ substrate for novel solar power conversion
}

The MIT Faculty has made this article openly available. Please share how this access benefits you. Your story matters.

As Published: $10.1063 / 1.5018082$

Publisher: AIP Publishing

Persistent URL: https://hdl.handle.net/1721.1/135782

Version: Final published version: final published article, as it appeared in a journal, conference proceedings, or other formally published context

Terms of Use: Article is made available in accordance with the publisher's policy and may be subject to US copyright law. Please refer to the publisher's site for terms of use. 


\section{InGaP solar cell on Ge-on-Si virtual substrate for novel solar power conversion ${ }^{\circ}$}

Cite as: J. Appl. Phys. 123, 085111 (2018); https://doi.org/10.1063/1.5018082

Submitted: 03 December 2017 . Accepted: 10 February 2018 . Published Online: 26 February 2018

T. W. Kim, B. R. Albert, L. C. Kimerling, and J. Michel

\section{COLLECTIONS}

EP This paper was selected as an Editor's Pick
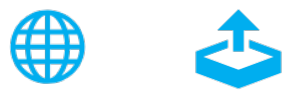

\section{ARTICLES YOU MAY BE INTERESTED IN}

Guest Editorial: The dawn of gallium oxide microelectronics

Applied Physics Letters 112, 060401 (2018); https://doi.org/10.1063/1.5017845

High-efficiency inverted metamorphic 1.7/1.1 eV GalnAsP/GalnAs dual-junction solar cells Applied Physics Letters 112, 053905 (2018); https://doi.org/10.1063/1.5008517

Luminescence of III-IV-V thin film alloys grown by metalorganic chemical vapor deposition Journal of Applied Physics 123, 175101 (2018); https://doi.org/10.1063/1.5016443

\section{Journal of Applied Physics Polymer-Grafted Nanoparticles}




\title{
InGaP solar cell on Ge-on-Si virtual substrate for novel solar power conversion
}

\author{
T. W. Kim, ${ }^{1, a)}$ B. R. Albert, ${ }^{2}$ L. C. Kimerling, ${ }^{1,2}$ and J. Michel ${ }^{1,2, a)}$ \\ ${ }^{1}$ Materials Processing Center, Massachusetts Institute of Technology, 77 Massachusetts Avenue, Cambridge, \\ Massachusetts 02139, USA \\ ${ }^{2}$ Department of Materials Science and Engineering, Massachusetts Institute of Technology, \\ 77 Massachusetts Avenue, Cambridge, Massachusetts 02139, USA
}

(Received 3 December 2017; accepted 10 February 2018; published online 26 February 2018)

\begin{abstract}
InGaP single-junction solar cells are grown on lattice-matched Ge-on-Si virtual substrates using metal-organic chemical vapor deposition. Optoelectronic simulation results indicate that the optimal collection length for InGaP single-junction solar cells with a carrier lifetime range of $2-5 \mathrm{~ns}$ is wider than approximately $1 \mu \mathrm{m}$. Electron beam-induced current measurements reveal that the threading dislocation density (TDD) of InGaP solar cells fabricated on Ge and Ge-on-Si substrates is in the range of $10^{4}-3 \times 10^{7} \mathrm{~cm}^{-2}$. We demonstrate that the open circuit voltage $\left(V_{o c}\right)$ of InGaP solar cells is not significantly influenced by TDDs less than $2 \times 10^{6} \mathrm{~cm}^{-2}$. Fabricated InGaP solar cells grown on a Ge-on-Si virtual substrate and a Ge substrate exhibit $V_{o c}$ in the range of 0.96 to $1.43 \mathrm{~V}$ under an equivalent illumination in the range of $\sim 0.5$ Sun. The estimated efficiency of the InGaP solar cell fabricated on the Ge-on-Si virtual substrate (Ge substrate) at room temperature for the limited incident spectrum spanning the photon energy range of $1.9-2.4 \mathrm{eV}$ varies from 16.6\% to 34.3\%. Published by AIP Publishing. https://doi.org/10.1063/1.5018082
\end{abstract}

\section{INTRODUCTION}

A novel approach for solar power conversion combines photovoltaic and solar thermal conversion techniques for a combined high-efficiency energy conversion and dispatchability, by directly generating electricity in a photovoltaic cell array and temporarily storing thermal energy in a heat transfer fluid. ${ }^{1}$ A spectrum splitting configuration enables the optimal use of the entire solar spectrum by directing each photon to the subsystem (photovoltaic or thermal) whose energy conversion is more efficient for the energy of the particular photon. ${ }^{2}$ Individual state-of-the-art approaches for solar energy conversion rely on either photovoltaic or thermal conversion processes alone, thus limiting their capacity to generate dispatchable power efficiently. Multi-junction photovoltaic cells minimize thermalization losses by reducing the average difference between the absorbed photon energy and the bandgap of the absorbing material. As multijunction cells include small bandgap junctions such as $\mathrm{Ge}$ and InGaAs, the efficiencies are more sensitive to elevated operating temperatures, especially when illuminated with concentrated sunlight.

A hybrid solar energy system consists of a dichroic mirror placed near the focal point of the parabolic dish concentration, which reflects only a limited part of the solar spectrum (in the range of $1.9-2.4 \mathrm{eV}$ ) toward the photovoltaic cells. An InGaP lattice matched to Ge provides a wide bandgap $\left(\mathrm{E}_{\mathrm{g}} \sim 1.85 \mathrm{eV}\right)$, corresponding to photon energies near the peak photon flux in the solar spectrum. In a hybrid

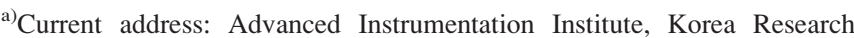
Institute of Standards and Science, 267 Gajeong-ro, Yuseong-gu, Daejeon 305-340, South Korea. Electronic addresses: twkim@kriss.re.kr and jmichel@mit.edu.
}

solar energy system, single-junction InGaP cells can absorb many photons near the bandgap energy (e.g., in the range of $1.9-2.4 \mathrm{eV}$ ) and convert their energy to electricity at high efficiency (estimated to be over $50 \%$ for room temperature operation). The remaining photons in the infrared and ultraviolet regions can be collected using a thermal receiver. By replacing the Ge substrate with a "virtual substrate" of a thin Ge film deposited on low-cost $\mathrm{Si}$ wafers, the cost component of high efficiency III-V photovoltaic of the system is significantly reduced. InGaP single-junction cells grown on Ge-on$\mathrm{Si}$ virtual substrates instead of expensive Ge wafers more typically used for III-V based solar cells can improve the economic prospects of the proposed hybrid system. A Si substrate also provides the additional advantages of higher thermal conductivity and mechanical robustness.

In order to maintain high solar cell performance, the threading dislocation density (TDD) of the solar cell layers must be restricted to low $10^{6} \mathrm{~cm}^{-2}$ levels, below which minority carrier lifetimes and open-circuit voltages in $\mathrm{InGaP}$ films are not adversely affected by threading dislocations. ${ }^{3}$ Growing high-quality InGaP films on Ge-on-Si virtual substrates requires good heteroepitaxy at both the III-V/Ge and $\mathrm{Ge} / \mathrm{Si}$ interfaces. High-quality Ge-on-Si heteroepitaxy is challenging owing to the large lattice-mismatch $(4.2 \%)$ and thermal mismatch between the two materials. There are two possible implementations of $\mathrm{Ge}-\mathrm{on}-\mathrm{Si}$ substrates. One method is based on a SiGe compositionally graded buffer which can achieve sufficiently low TDDs $\left(\sim 10^{6} \mathrm{~cm}^{-2}\right)$ but requires a thickness of over $10 \mu \mathrm{m}$ and exhibits a strainrelated cross hatch. ${ }^{3-5}$ An alternative method employs a two-step epitaxial Ge growth followed by cyclic thermal annealing, resulting in thinner films (e.g., $1 \mu \mathrm{m}$ ) with TDDs of $2 \times 10^{7} \mathrm{~cm}^{-2}$ and $2 \times 10^{6} \mathrm{~cm}^{-2}$ for blanket and selective 
area films, respectively. ${ }^{6}$ Herein, we present an InGaP solar cell structure grown via metal-organic chemical vapor deposition (MOCVD) on both Ge and Ge-on-Si virtual substrates, which are grown using the two-step growth and annealing processes.

\section{OPTIMIZATION OF THE InGaP SOLAR CELL STRUCTURE}

The performance of an InGaP cell grown on a Ge-on-Si substrate is sensitive to the thickness of the base region owing to the shorter minority carrier lifetime attributed to a high TDD $\left(>10^{6} \mathrm{~cm}^{-2}\right)$. Thus, the thickness of the base region is optimized for a range of minority carrier lifetimes using commercial TCAD software (Crosslight APSYS) as shown in Fig. 1. The power generation of a solar cell is improved when the thickness of the base region is increased until it is smaller than the sum of the depletion region width and the carrier diffusion length. According to literature, the minority carrier lifetimes of InGaP materials grown on $\mathrm{GaAs}$ substrates, associated with extremely low TDDs (less than $10^{3} \mathrm{~cm}^{-2}$ ), are $5.6 \mathrm{~ns}$ (Ref. 7) and $10 \mathrm{~ns}{ }^{8}$ The optimal collection lengths (sum of the depletion region width and the diffusion length) of InGaP single-junction solar cells are $1.5 \mu \mathrm{m}$, $1.5 \mu \mathrm{m}$, and $0.7 \mu \mathrm{m}$ for the lifetimes of $10 \mathrm{~ns}, 5 \mathrm{~ns}$, and $2 \mathrm{~ns}$, respectively. If we assume the minority carrier lifetime in the range of $2-5 \mathrm{~ns}$ for $\mathrm{InGaP}$ cells grown on a Ge-on-Si virtual substrate (TDD $\sim 10^{7} \mathrm{~cm}^{-2}$ ), owing to a higher TDD in comparison to that of cells grown on a GaAs substrate, we estimate the optimal collection length to be approximately $1 \mu \mathrm{m}$.

\section{EXPERIMENTAL METHODS}

Blanket Ge-on-Si virtual substrates were grown via ultra-high-vacuum chemical vapor deposition. Si (100) substrates, miscut $6^{\circ}$ toward (111), underwent an RCA cleaning procedure, involving organic cleaning in $\mathrm{NH}_{4} \mathrm{OH}: \mathrm{H}_{2} \mathrm{O}_{2}: \mathrm{H}_{2} \mathrm{O}$ $(1: 1: 5)$ at $80^{\circ} \mathrm{C}$, chemical oxide removal in $\mathrm{HF}: \mathrm{H}_{2} \mathrm{O}(1: 50)$, and metallic cleaning in $\mathrm{HCl}: \mathrm{H}_{2} \mathrm{O}_{2}: \mathrm{H}_{2} \mathrm{O}(1: 1: 6)$ at $80^{\circ} \mathrm{C}$, along with the removal of a second chemical oxide again in

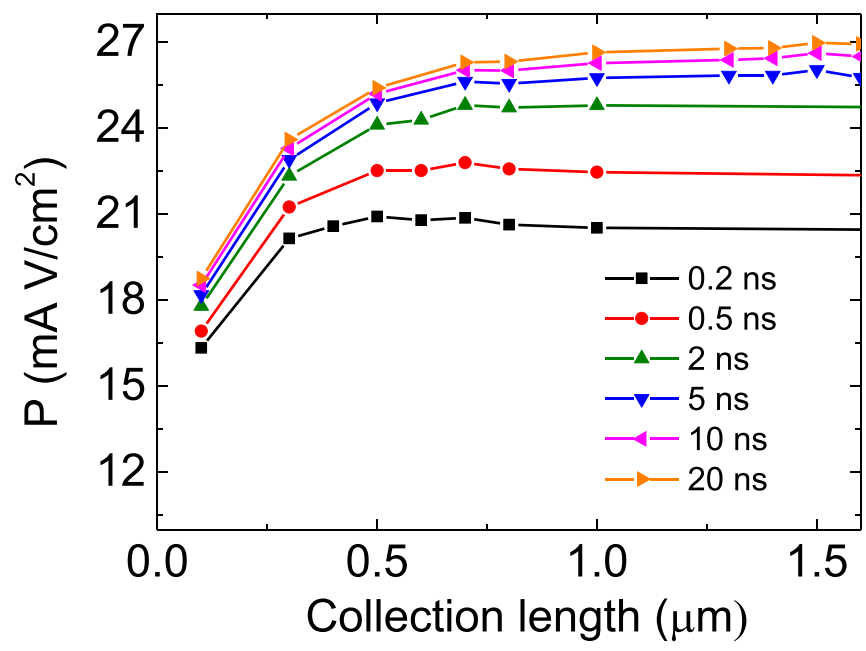

FIG. 1. Power density of the InGaP solar cell versus collection length (sum of the depletion region width and the diffusion length) for various minority carrier lifetimes ( $\tau=0.2 \mathrm{~ns}-20 \mathrm{~ns})$. dilute HF. Wafers were placed in a multi-wafer boat and introduced to the process chamber through a load lock under vacuum. After baking at $800^{\circ} \mathrm{C}$, the chamber temperature was reduced to $350{ }^{\circ} \mathrm{C}$ to grow the low-temperature buffer layer using pure $\mathrm{GeH}_{4}$. The low-temperature buffer plastically relaxed the majority of the misfit strain between the Ge film and the Si substrate. After the thickness of the buffer layer reached $80 \mathrm{~nm}$, the chamber temperature was increased to $730{ }^{\circ} \mathrm{C}$. High-temperature Ge growth was conducted using pure $\mathrm{GeH}_{4}$ at a pressure of $2.0 \times 10^{-2}$ mbar until a layer thickness of at least $1 \mu \mathrm{m}$ was reached. The chamber temperature was thereafter increased to $850{ }^{\circ} \mathrm{C}$ to facilitate dislocation glide, fusion, and annihilation to reduce the TDD in the Ge film from an initial level of $\sim 10^{9} \mathrm{~cm}^{-2}$ to $2 \times 10^{7} \mathrm{~cm}^{-2}$.

Single-junction InGaP cells were grown on (100)-oriented $\mathrm{Ge}$ and $\mathrm{Ge}-\mathrm{on}-\mathrm{Si}$ virtual substrates in a vertical chamber close-coupled showerhead-MOCVD reactor with a misorientation of $6^{\circ}$ toward (111) to avoid the antiphase domain boundary. The structure of the InGaP single-junction solar cell consisted of a GaAs buffer layer $(600 \mathrm{~nm})$ to initiate III-V growth on Ge, wide bandgap $\mathrm{Al}_{0.5} \mathrm{In}_{0.5} \mathrm{P}(50 \mathrm{~nm})$ to create a back-surface field, a lightly doped thick $\operatorname{In}_{0.5} \mathrm{Ga}_{0.5} \mathrm{P}$ base $(1000 \mathrm{~nm})$, a heavily doped thin $\operatorname{In}_{0.5} \mathrm{Ga}_{0.5} \mathrm{P}$ emitter $(100 \mathrm{~nm})$, an $\mathrm{Al}_{0.5} \mathrm{In}_{0.5} \mathrm{P}$ window layer $(30 \mathrm{~nm})$, and a highly doped GaAs contact layer as shown in Fig. 2. Trimethyl gallium and trimethyl indium were used as group III precursors, whereas arsine $\left(\mathrm{AsH}_{3}\right)$ and phosphine $\left(\mathrm{PH}_{3}\right)$ are used as group $\mathrm{V}$ precursors. Disilane $\left(\mathrm{Si}_{2} \mathrm{H}_{6}\right)$ was used as the n-doping source for n-InGaP, n-AlInP, and n-GaAs films. Diethyl zinc was used as the p-doping source for $\mathrm{p}$-InGaP, $\mathrm{p}$-AlInP, and pGaAs. For the growth of the solar cell structure, the reactor pressure was maintained at 100 Torr at the growth temperature of $650{ }^{\circ} \mathrm{C}$. Gas phase molar flow ratios for the $\mathrm{InGaP}$ collection region were established as follows: $\mathrm{V} / \mathrm{III}=374.8$,

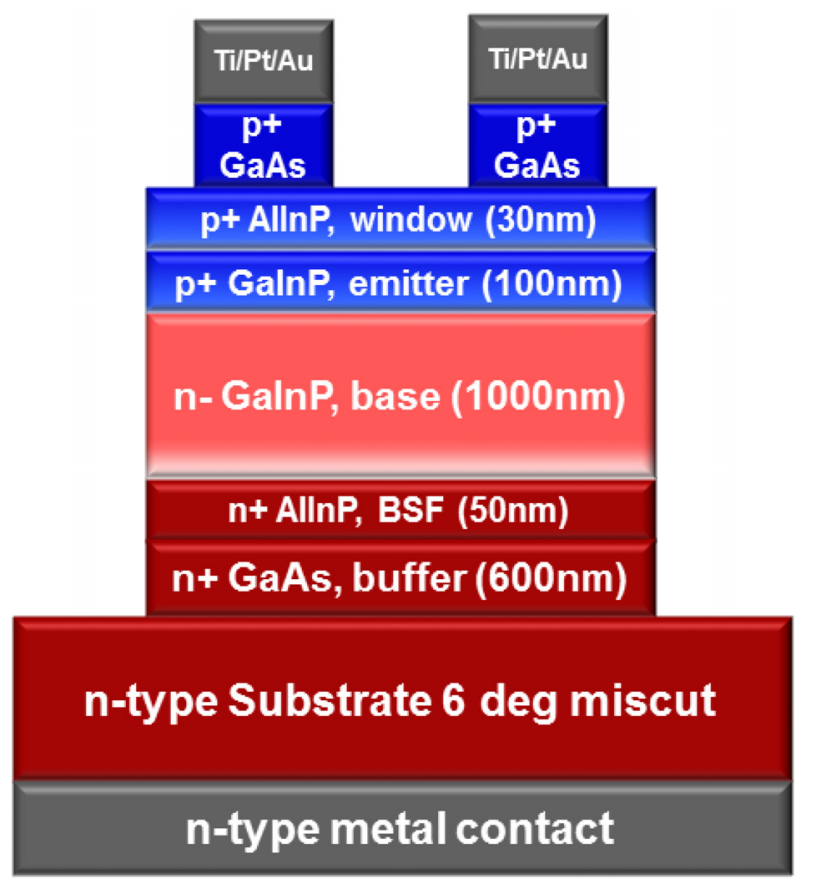

FIG. 2. Schematic design for the InGaP single-junction solar cell structure on $\mathrm{Ge}$ and $\mathrm{Ge}$-on-Si substrates. 
$\mathrm{In} / \mathrm{III}=0.556$, and $\mathrm{Si} / \mathrm{Ga}=0.026, \mathrm{Zn} / \mathrm{Ga}=0.048$ for $\mathrm{n}$-type and p-type doping, respectively.

High-resolution X-ray diffraction (HRXRD) $\omega-2 \theta$ rocking curves around the $\left(\begin{array}{lll}0 & 0 & 4\end{array}\right)$ reflection were used to characterize the out-of-plane lattice constant of the InGaP film. Nominally, lattice-matched $(\Delta \mathrm{a} / \mathrm{a}<0.03 \%)$ InGaP films grown on $\mathrm{Ge}$ and GaAs substrates with a single-junction structure were utilized. The InGaP solar cell structure on a Ge-on-Si virtual substrate was further investigated using triple-axis X-ray diffraction analysis by measuring the symmetric ( $\left.\begin{array}{lll}0 & 0 & 4\end{array}\right)$ and asymmetric (2 24$)$ reciprocal space maps (RSMs), which determines the out-of-plane and in-plane lattice parameters of each layer, degree of lattice relaxation, tilt behavior, and defect-induced mosaic broadening.

The $\mathrm{n}$ - and p-type contact metals were $\mathrm{TiO}_{2} / \mathrm{Ti}(5 \mathrm{~nm} /$ $300 \mathrm{~nm})$ and $\mathrm{Ti} / \mathrm{Pt} / \mathrm{Au}(10 \mathrm{~nm} / 20 \mathrm{~nm} / 300 \mathrm{~nm})$, respectively. The purpose of the thin $\mathrm{TiO}_{2}$ layer was to reduce the effects of Fermi level pinning between n-Ge and the back metal contact, thus avoiding a Schottky contact. ${ }^{9}$ The total area of the solar cell was $0.49 \mathrm{~cm}^{2}\left(7 \times 7 \mathrm{~mm}^{2}\right)$, and the aperture area, excluding bus lines, was $0.42 \mathrm{~cm}^{2}$. After fabrication, individual photovoltaic cells were characterized using current-voltage (I-V) scans with and without illumination. For I-V measurements, an HP4145A semiconductor analyzer was used to sweep the voltage between the top and bottom contact SMU probes and measure the current flow through the cell. A xenon arc lamp was used for measurements under illumination. The power of the lamp produced an equivalent flux corresponding to the illumination of approximately 0.5 Sun for a calibrated c-Si singlejunction cell. External quantum efficiency (EQE) measurements were obtained using a broadband halogen light source, a grating monochromator, and optical filters to remove higher-order grating reflections. The input photon flux was calibrated using a Si reference cell for which the EQE had been previously measured. The TDDs in fabricated InGaP solar cells were investigated using plan-view electron-beam-induced current (EBIC) imaging with a Helios NanoLab scanning electron microscope operating at $15 \mathrm{kV}$ and $2.7 \mathrm{nA}$ with a Stanford Research Systems SR-570 low-noise current amplifier.

\section{RESULT AND DISCUSSION}

A study focusing on GaAs solar cells with varying TDDs has shown that above TDDs of $10^{6} \mathrm{~cm}^{-2}$, minority carrier lifetimes begin to be adversely affected, thus reducing the photovoltaic efficiencies. ${ }^{10}$ Similar thresholds for minority carrier lifetimes exist for other III-V materials such as InGaP. ${ }^{11}$ The overall minority carrier lifetime in a film with a substantial TDD can be estimated by adding the recombination rate intrinsic to the material in the absence of defects and an additional recombination rate due to threading dislocations

$$
\begin{aligned}
\frac{1}{\tau_{n, p}} & =\frac{1}{\tau_{n, p}^{0}}+\frac{1}{\tau_{T D D}}, \\
\tau_{T D D} & =\frac{4}{\pi^{3}(T D D s) D},
\end{aligned}
$$

where for the p-type material, the electron (hole) diffusion coefficient $\left(D_{n}\left(D_{h}\right)\right)$ is $27.816(1.036) \mathrm{cm}^{2} / \mathrm{s}$ and the peak minority electron (hole) lifetime $\left(\tau_{n}^{0}\left(\tau_{h}^{0}\right)\right)$ is 10 (1)ns for InGaP. ${ }^{8,11}$ Using these parameters, the minority carrier lifetime can be estimated as a function of TDD for n-type InGaP as shown in Fig. 3. The minority carrier lifetime of p-type (ntype) InGaP films as the base region is significantly decreased when the TDD was higher than $10^{6}\left(10^{7}\right) \mathrm{cm}^{-2}$. As epitaxial films inherit the threading dislocations from the substrate, the TDD in the Ge virtual substrate must also be below the threshold for the relevant III-V layers to be deposited.

Figure 4(a) reveals that the HRXRD peak positions of $\mathrm{Ge}, \mathrm{InGaP}, \mathrm{GaAs}$, and $\mathrm{Si}$ substrates are distinctly visible. Both the $\mathrm{InGaP}$ and $\mathrm{GaAs}$ peak positions corresponding to $\mathrm{Ge}$ indicate nominal lattice-matching $(\Delta \mathrm{a} / \mathrm{a}<0.03 \%)$ of the films. The symmetric $\left(\begin{array}{lll}0 & 0 & 4\end{array}\right)$ RSM exhibits two distinct reciprocal lattice point maxima in accordance with the $\mathrm{In}_{0.504} \mathrm{Ga}_{0.496} \mathrm{P} /$ $\mathrm{GaAs} / \mathrm{Ge}$ epi-layers and $\mathrm{Si}$ substrate, as shown in Fig. 4(b). The degree of relaxation of $\mathrm{Ge}$ is estimated by measuring the out-of-plane and in-plane lattice constants from the symmetric

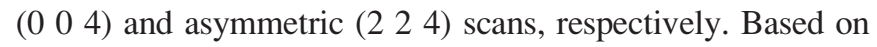
the measured RSM of $\operatorname{In}_{0.504} \mathrm{Ga}_{0.496} \mathrm{P} / \mathrm{GaAs} / \mathrm{Ge}$ epi-layers in the region of the asymmetric (2 24 ) Si substrate peak, both $\mathrm{Ge}$ as a virtual substrate and $\mathrm{In}_{0.504} \mathrm{Ga}_{0.496} \mathrm{P} / \mathrm{GaAs}$ epi-layers are fully relaxed $(\sim 92 \%)$ with respect to the $\mathrm{Si}$ substrate.

Figure 5(a) shows the EBIC image of a fabricated InGaP solar cell grown on a Ge substrate, showing a low TDD value of $4.1 \times 10^{4} \mathrm{~cm}^{-2}$. Unintentionally introduced threading dislocations due to an initial transient in the indium content of the InGaP film grown on the GaAs III-V initiation layer caused a moderate TDD level of $3.5 \times 10^{6} \mathrm{~cm}^{-2}$, as shown in Fig. 5(b). Figures 5(c) and 5(d) show the EBIC images of InGaP solar cells grown on blanket and coalesced selectively grown Ge-on-Si virtual substrates, ${ }^{12}$ indicating relatively high TDD values of $1.5 \times 10^{7} \mathrm{~cm}^{-2}$ and $2.5 \times 10^{7} \mathrm{~cm}^{-2}$, respectively. As the TDDs of InGaP films extracted from EBIC are in close agreement with TDDs of Ge-on-Si virtual substrates measured by defect decoration of the Ge surface using nitric acid, hydrofluoric acid, acetic acid, and iodine, ${ }^{12}$ the TDD of InGaP films can serve as an effective proxy to probe the defect density at the surface of Ge-on-Si virtual substrates.

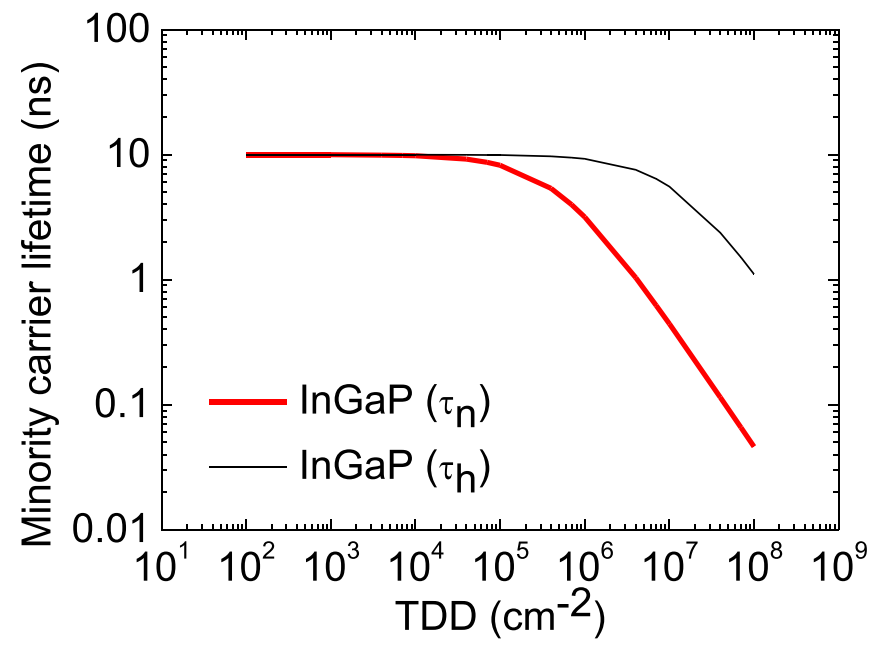

FIG. 3. Minority carrier lifetime dependence on TDDs for the InGaP solar cell. 


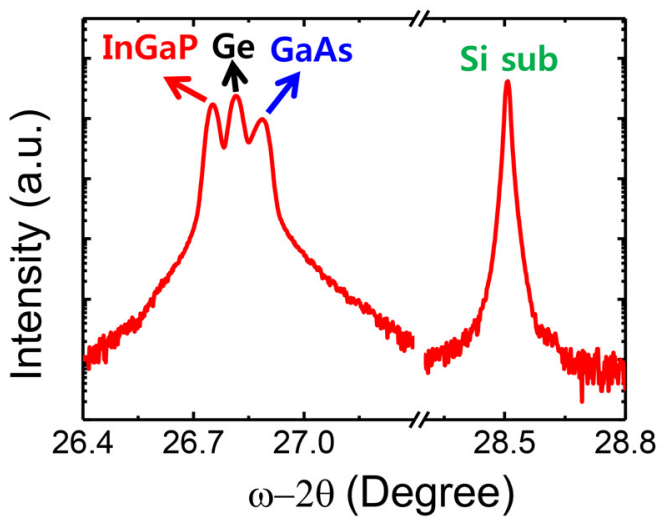

(a)

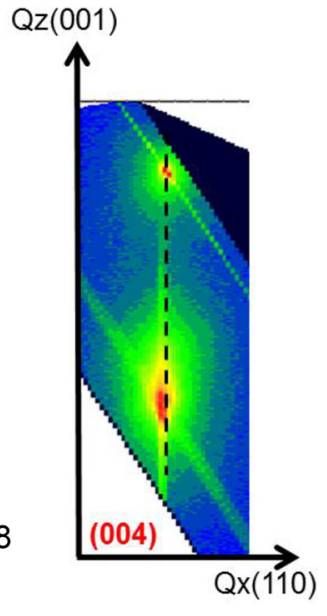

(b)

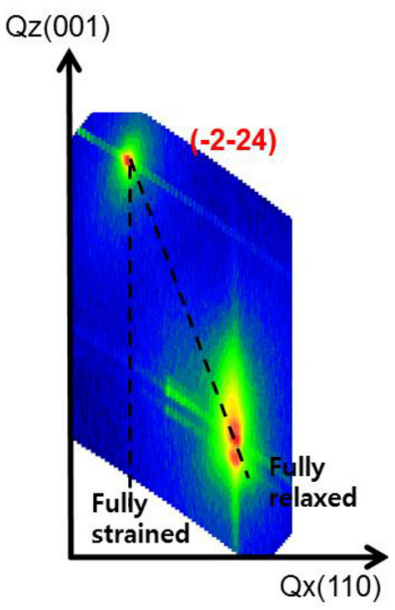

(c)

FIG. 4. (a) $\left(\begin{array}{lll}0 & 0 & 4\end{array}\right)$ HRXRD analysis and (b) symmetric $\left(\begin{array}{lll}0 & 0 & 4\end{array}\right)$ and (c) asymmetric $\left(\begin{array}{lll}2 & 2 & 4\end{array}\right)$ RSM of the InGaP solar cell on a patterned Ge-on-Si virtual substrate.

Figure 6(a) shows the performance results of $\mathrm{InGaP}$ solar cells illuminated with approximately 0.5 Sun flux at room temperature $(300 \mathrm{~K})$. The $\mathrm{InGaP}$ solar cells grown on Ge substrates with a cell size of $49 \mathrm{~mm}^{2}$ exhibit open-circuit

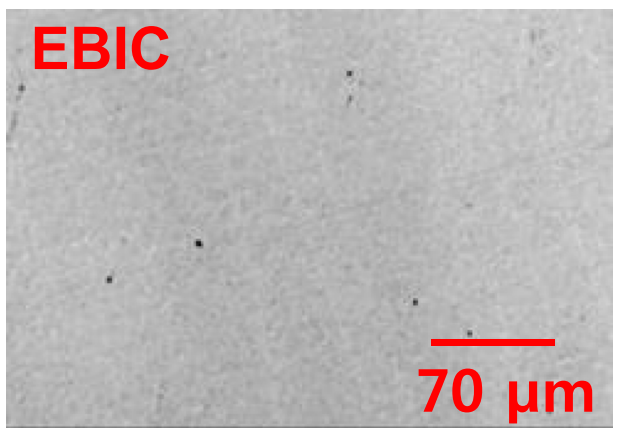

TDD 4.1 $\times 10^{4} \mathrm{~cm}^{-2}$

(a)

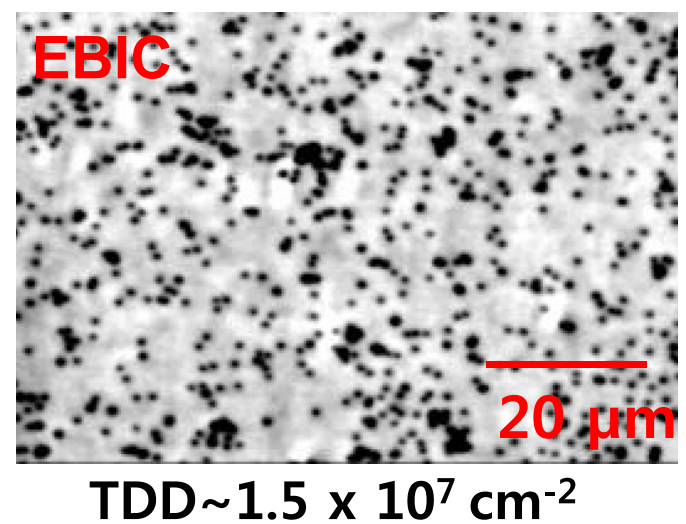

(c) voltages $\left(V_{o c}\right)$ as high as $1.43 \mathrm{~V}(1.33 \mathrm{~V}$ for the sample with moderate TDD), which is comparable to the results of the InGaP solar cell grown on GaAs $\left(\mathrm{TDD}<1.5 \times 10^{3} \mathrm{~cm}^{-2}\right.$ $\left.V_{o c} \sim 1.39 \mathrm{~V}\right)$ and $\mathrm{SiGe}$ substrates $\left(\mathrm{TDD} \sim 1-7 \times 10^{6} \mathrm{~cm}^{-2}\right.$

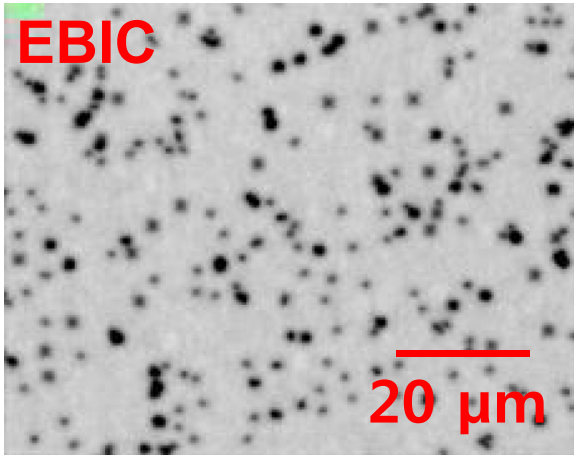

TDD 3.6 $\times 10^{6} \mathrm{~cm}^{-2}$

(b)

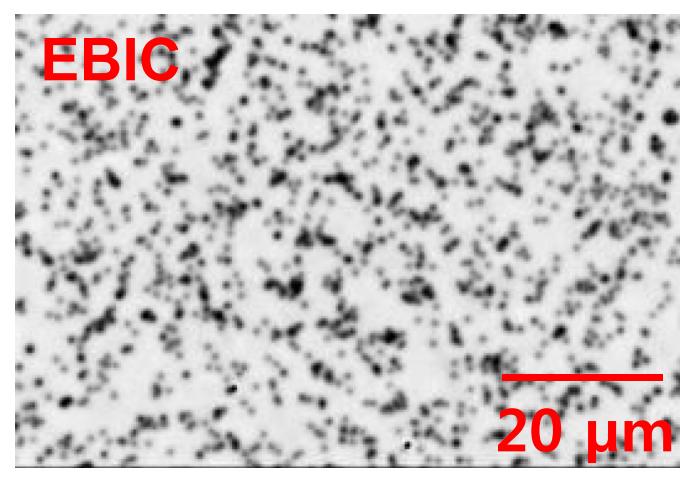

TDD $2.5 \times 10^{7} \mathrm{~cm}^{-2}$

(d)

FIG. 5. EBIC images of the InGaP solar cell on (a) a Ge substrate, (b) a Ge substrate with high TDDs due to the non-optimized growth sequence, (c) a blanket Ge-on-Si substrate, and (d) a patterned Ge-on-Si substrate. 
(a)

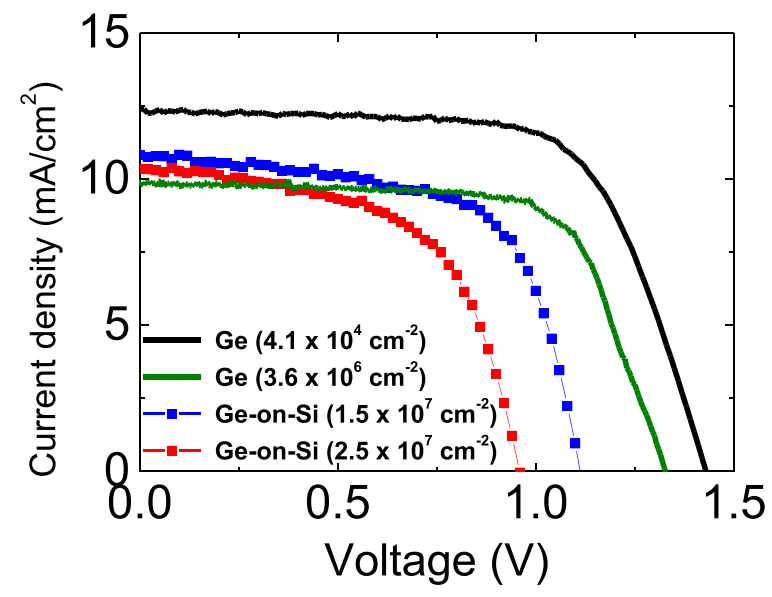

(b)

(c)
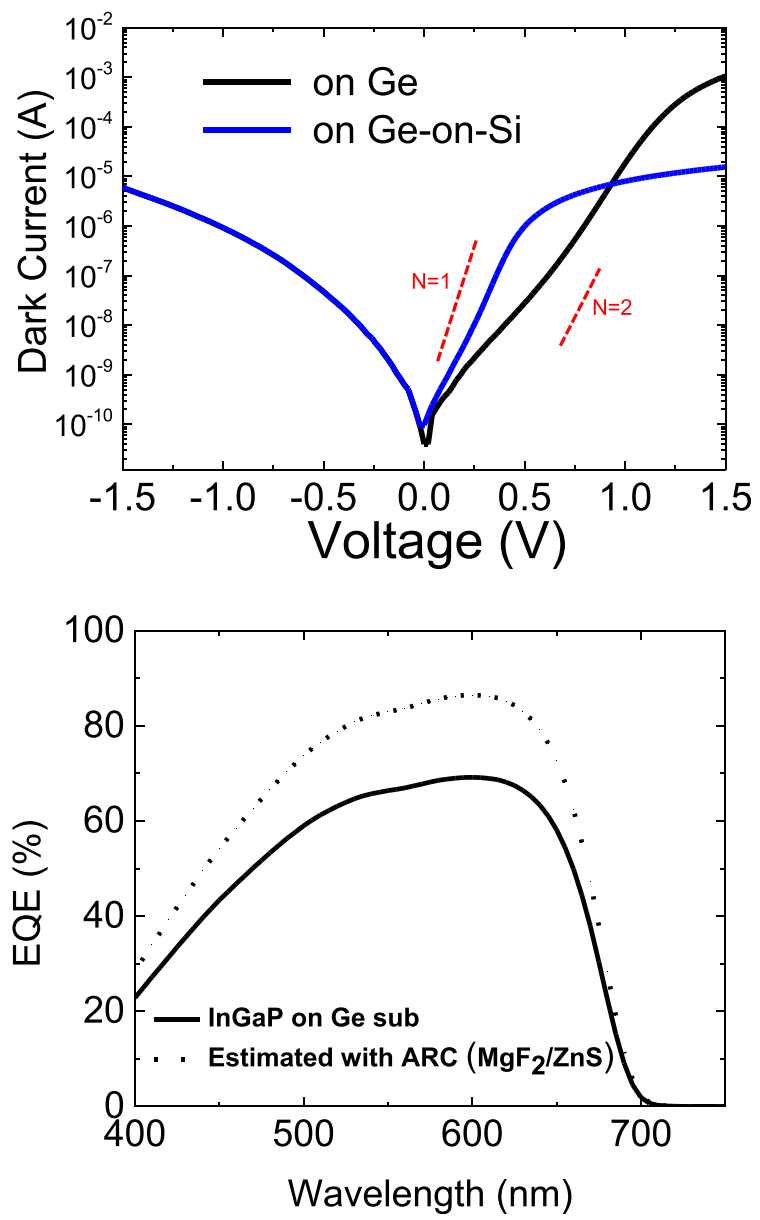

FIG. 6. (a) Photocurrent-voltage properties of the InGaP solar cells without anti-reflection coating under 0.5 Sun equivalent illumination. (b) Semilog dark current-voltage for InGaP cells on Ge and blanket Ge-on-Si substrates. (c) External quantum efficiencies of the InGaP single-junction solar cell on a Ge substrate (TDD $\sim 4.1 \times 10^{4}$ ) without ARC and with ARC.

and $\left.V_{o c} \sim 1.3 \mathrm{~V}\right)$, as reported by Geisz et al. ${ }^{13}$ and Andre, ${ }^{3}$ respectively. Cells grown on $\mathrm{Ge}$-on-Si virtual substrates exhibit $V_{o c} \mathrm{~s}$ of $1.15 \mathrm{~V}$ and $0.96 \mathrm{~V}$ for the TDD values of $1.5 \times 10^{7} \mathrm{~cm}^{-2}$ and $2.5 \times 10^{7} \mathrm{~cm}^{-2}$, respectively. Figure $6(\mathrm{~b})$ compares the dark current-voltage characteristics of InGaP cells grown on $\mathrm{Ge}$ and blanket Ge-on-Si substrates. Both curves indicate suppressed current values toward higher voltages, which possibly reflect the high series resistance at metal contacts. At low voltage, the InGaP diode on Ge-on-Si substrate shows a significantly shallower slope compared to that of the diode on a Ge substrate with the ideality factor of $\sim 2$, the cause of which seems to be the large amount of Shockley-Read-Hall (SRH) recombination accompanying a higher TDD level. The measured EQE of the InGaP solar cell on a Ge substrate indicates an extended EQE spectral response in the 400-700 $\mathrm{nm}$ range, as shown in Fig. 6(c). The estimated EQE spectral response with the anti-reflection coating (ARC) $\left(\mathrm{MgF}_{2} / \mathrm{ZnS}\right)$ of the $\mathrm{InGaP}$ solar cell revealed a similarly high efficiency $(\sim 90 \%)$ result which was represented by Takamoto et al. ${ }^{8}$ The $V_{o c}$ of InGaP solar cells on a Ge substrate provides a good indication of the acceptable III-V semiconductor material quality possible if a lattice-matched substrate free of threading dislocations is provided. As the TDD value of the InGaP active region increases, $V_{o c}$ is only influenced at TDD levels above $2 \times 10^{6} \mathrm{~cm}^{-2}$, as indicated in Fig. 7(a). The offset $\left(\mathrm{W}_{\mathrm{oc}}\right)$ values between $V_{o c}$ and $\mathrm{E}_{\mathrm{g}}$ are used for the quantitative analysis of material quality and to estimate the amount of SRH recombination. ${ }^{14,15} \mathrm{We}$ find that the $\mathrm{InGaP}$ solar cell on

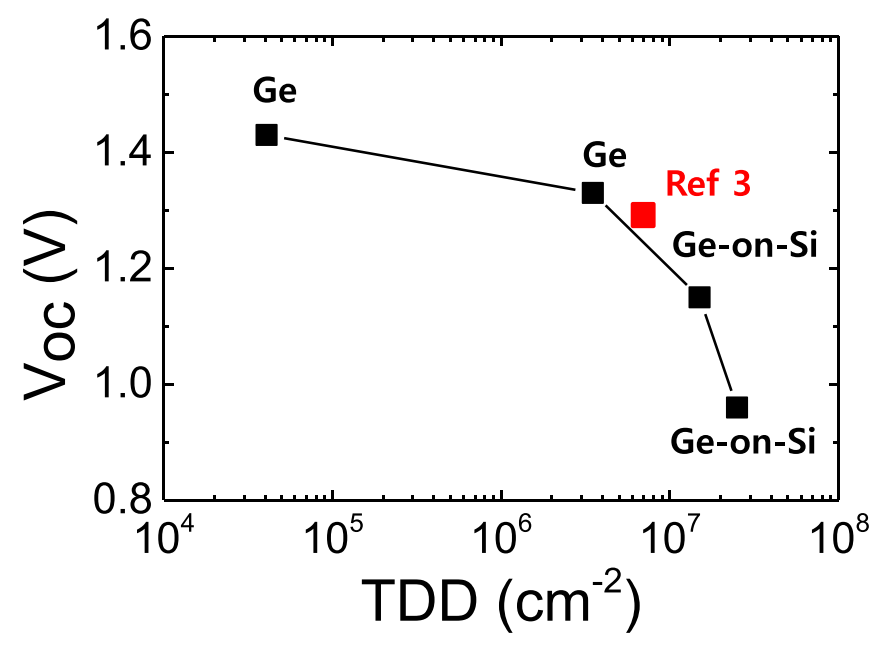

(a)

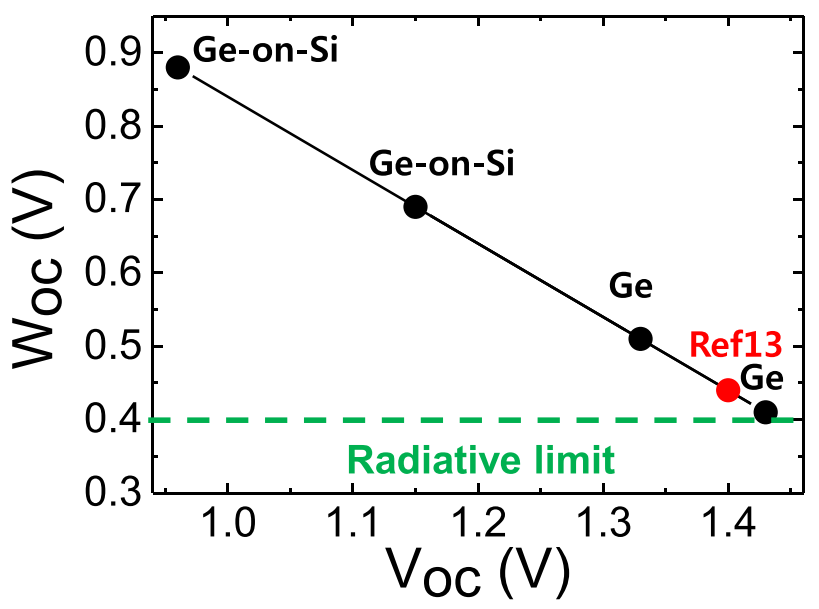

(b)

FIG. 7. (a) Open circuit voltage $\left(\mathrm{V}_{\mathrm{oc}}\right)$ dependence on TDDs and (b) offset values $\left(\mathrm{W}_{\mathrm{oc}}\right.$ ) between the $\mathrm{V}_{\mathrm{oc}}$ and $\mathrm{E}_{\mathrm{g}}$ dependence on open circuit voltage for the InGaP solar cell on Ge and Ge-on-Si virtual substrates. Also shown are the measured $\mathrm{W}_{\mathrm{oc}}$ value from previous studies. ${ }^{3,13}$ 
TABLE I. Summary of performance results and TDDs of InGaP solar cells on various substrates.

\begin{tabular}{|c|c|c|c|c|c|}
\hline Substrate & $\mathrm{V}_{\mathrm{oc}}(\mathrm{V})$ & $\mathrm{FF}(\%)$ & TDDs $\left(\mathrm{cm}^{-2}\right)$ & $\mathrm{W}_{\mathrm{oc}}(\mathrm{V})$ & Estimated $\eta 1.9 \mathrm{eV}$ to $2.4 \mathrm{eV}(\%)$ \\
\hline $\mathrm{Ge}$ & 1.43 & 66.7 & $4.1 \times 10^{4}$ & 0.41 & 34.3 \\
\hline Ge with moderate TDDs & 1.33 & 70.5 & $3.6 \times 10^{6}$ & 0.51 & 26.4 \\
\hline Blanket Ge-on-Si & 1.15 & 61.7 & $1.5 \times 10^{7}$ & 0.69 & 22.1 \\
\hline Patterned Ge-on-Si & 0.96 & 57.9 & $2.5 \times 10^{7}$ & 0.88 & 16.6 \\
\hline Ref 13 w/ARC (on GaAs) & 1.40 & 88.3 & $<10^{3}$ & 0.44 & 50.3 \\
\hline
\end{tabular}

Ge-on-Si yields higher $\mathrm{W}_{\mathrm{oc}}$ values of 0.88 and $0.69 \mathrm{~V}$, compared to those on a Ge substrate $\left[\mathrm{W}_{\mathrm{oc}}\right.$ values of 0.41 and $0.51 \mathrm{~V}$, which are comparable to that of the InGaP cell on GaAs $\left(\mathrm{W}_{\mathrm{oc}}\right.$ of $\left.\left.0.44 \mathrm{~V}\right)\right],{ }^{13}$ due to poor minority carrier lifetime associated with high TDD levels (above $2 \times 10^{6} \mathrm{~cm}^{-2}$ ), which aligned with the expectations displayed in Fig. 7(b)

$$
\text { Efficiency }=\frac{V_{o c} \times J_{s c} \times F F}{\text { Solar power AM1.5D517-652nmwavelength }} .
$$

The expected efficiency of the InGaP solar cell operating with a limited incidence spectrum from $1.9 \mathrm{eV}(652 \mathrm{~nm})$ to $2.4 \mathrm{eV}$ $(517 \mathrm{~nm})$ for use in a hybrid solar converter is considered in the calculation of the overall efficiency of the InGaP cell as shown in Eq. (3). Ideally, the performance of an InGaP cell on a GaAs substrate (TDD $<10^{3} \mathrm{~cm}^{-2}$ ) possesses a $V_{o c}$ of 1.4 , a $J_{s c}$ of $14.8 \mathrm{~mA} / \mathrm{cm}^{2}$, and a $88.3 \%$ fill factor, ${ }^{13}$ indicating an estimated overall efficiency of $50.3 \%$. The estimated overall efficiency values of InGaP cells on various substrates under 1 sun at room temperature are $34.3 \%, 26.4 \%$, $22.1 \%$, and $16.6 \%$ for cells on a Ge substrate $(\mathrm{TDD}<4.1$ $\left.\times 10^{4} \mathrm{~cm}^{-2}\right)$, Ge $\left(\right.$ TDD $\left.<3.6 \times 10^{6} \mathrm{~cm}^{-2}\right)$, Ge-on-Si (TDD $<1.5 \times 10^{7} \mathrm{~cm}^{-2}$ ), and Ge-on-Si (TDD $<2.5 \times 10^{7} \mathrm{~cm}^{-2}$ ), respectively, as shown in Table I. The relatively low fill factor and the estimated overall efficiency of all InGaP solar cells on Ge and Ge-on-Si substrates likely stem from the series resistance due to the unoptimized top and bottom metal contacts and high TDDs. Further optimization of the Ge growth process, including the use of selectively grown Ge-on-Si substrates, is still required to reduce the TDD to the acceptable level of $2 \times 10^{6} \mathrm{~cm}^{-2}$ where threading dislocations do not degrade the efficiency of InGaP solar cells.

\section{CONCLUSIONS}

InGaP single-junction solar cells have been fabricated on $\mathrm{Ge}$ and Ge-on-Si virtual substrates to be used in high efficiency hybrid solar power conversion systems. Simulations indicated an optimum base layer thickness of $1 \mu \mathrm{m}$ for InGaP solar cells, assuming a minority carrier lifetime in the range of $2-5 \mathrm{~ns}$. Reductions of the measured $V_{o c}$ of $\mathrm{InGaP}$ single-junction solar cells are directly linked to the increased TDD levels in the active region as measured using EBIC. The InGaP single-junction solar cells grown on $\mathrm{Ge}$, Ge with moderate TDD and Ge-on-Si virtual substrates with TDD levels of $4.1 \times 10^{4}, 3 \times 10^{6}$, and $1.5 \times 10^{7} \mathrm{~cm}^{-2}$, respectively, exhibited open-circuit voltages of $1.43,1.33$, and $1.15 \mathrm{~V}$, respectively. In order to achieve high efficiencies, the TDD of Ge virtual substrates must be limited to approximately $2 \times 10^{6} \mathrm{~cm}^{-2}$ or less. The development of InGaP solar cells on a Ge-on-Si virtual substrate with low TDD levels has the potential to result in significant cost reductions in III-V photovoltaic-based hybrid solar energy systems.

\section{ACKNOWLEDGMENTS}

This work was carried out in part through the use of MIT's Microsystems Technology Laboratories and MIT's Substrate Engineering Laboratory. The information, data, or work presented herein was funded by the Advanced Research Projects Agency - Energy (ARPA-E), U.S. Department of Energy, under Award No. DE-AR0000472.

${ }^{1}$ H. M. Branz, W. Regan, K. J. Gerst, J. B. Borak, and E. A. Santoria, Energy Environ. Sci. 8, 3083-3091 (2015).

${ }^{2}$ L. Z. Broderick, T. Zhang, M. Stefancich, B. R. Albert, E. Wang, G. Chen, P. Armstrong, M. Chiesa, L. Kimerling, and J. Michel, Mater. Res. Soc. Symp. Proc. 1493, 31-36 (2013).

${ }^{3}$ C. L. Andre, "III-V semiconductors on SiGe substrates for multi-junction photovoltaic," Ph.D. thesis (The Ohio State University, Columbus, 2004).

${ }^{4}$ S. A. Ringel, J. A. Carlin, C. L. Andre, M. K. Hudait, M. Gonzalez, D. M. Wilt, E. B. Clark, P. Jenkins, D. Scheiman, A. Allerman, E. A. Fitzerald, and C. W. Leitz, Prog. Photovoltaics 10, 417-426 (2002).

${ }^{5}$ M. R. Lueck, C. L. Andre, A. J. Pitera, M. L. Lee, E. A. Fitzgerald, and S. A. Ringel, IEEE Electron Device Lett. 27, 142-144 (2006).

${ }^{6}$ H.-C. Luan, D. R. Lim, K. K. Lee, K. M. Chen, J. G. Sandland, K. Wafa, and L. C. Kimerling, Appl. Phys. Lett. 75, 2909 (1999).

${ }^{7}$ C. M. Fetzer, R. T. Lee, G. B. Stringfellow, X. Q. Liu, A. Sasaki, and N. Ohno, J. Appl. Phys. 91, 199 (2002).

${ }^{8}$ T. Takamoto, E. Ikeda, H. Kurita, and M. Ohmori, Sol. Energy Mater. Sol. Cells 35, 25-31 (1994).

${ }^{9}$ J.-Y. J. Lin, A. M. Roy, A. Nainani, Y. Sun, and K. C. Saraswat, Appl. Phys. Lett. 98, 092113 (2011).

${ }^{10}$ C. L. Andre, D. M. Wilt, A. J. Pitera, M. L. Lee, E. A. Fitzgerald, and S. A. Ringel, J. Appl. Phys. 98, 014502 (2005).

${ }^{11}$ N. Jain and M. K. Hudait, IEEE J. Photovoltaics 3, 528 (2013).

${ }^{12}$ A. Brian Ross, "Germanium on silicon heteroepitaxy for high efficiency photovoltaic devices," Ph.D. thesis (The Massachusetts Institute of Technology, Cambridge, 2016).

${ }^{13}$ J. F. Geisz, M. A. Steiner, I. Garcia, S. R. Kurtz, and D. J. Friedman, Appl. Phys. Lett. 103, 041118 (2013).

${ }^{14}$ R. R. King, D. Bhusari, A. Boca, D. Larrabee, X.-Q. Liu, W. Hong, C. M. Fetzer, D. C. Law, and N. H. Karam, Prog. Photovoltaics 19, 797 (2011).

${ }^{15}$ R. R. King, D. C. Law, K. M. Edmondson, C. M. Fetzer, G. S. Kinsey, H. Yoon, R. A. Sherif, and N. H. Karam, Appl. Phys. Lett. 90, 183516 (2007). 